\title{
Proper Care, Husbandry, and Breeding Guidelines for the Zebra Finch, Taeniopygia guttata
}

\author{
Christopher R. Olson, Morgan Wirthlin, Peter V. Lovell, and Claudio V. Mello ${ }^{1}$ \\ Department of Behavioral Neuroscience, Oregon Health and Science University, Portland, Oregon 97239
}

The zebra finch Taeniopygia guttata castanotis is a songbird commonly used in the laboratory, particularly for studies of vocal learning, neurobiology, and physiology. Within the laboratory, it is important to adopt careful husbandry practices that allow for normal development of the birds. For example, their song is a learned trait, passed culturally from adult males to juveniles, and thus its learning can be influenced by the health and social conditions of the birds present in the laboratory. Here we present guidelines for the successful maintenance and breeding of captive zebra finches.

\section{MATERIALS}

It is essential that you consult the appropriate Material Safety Data Sheets and your institution's Environmental Health and Safety Office for proper handling of equipment and hazardous materials used in this protocol.

\section{Reagents}

Bark (optional; see Step 8)

Chicken egg (scrambled; cooked in a microwave, 1-2 min)

Cuttlebone

Disinfectant (1\% Nolvasan [chlorhexidine diacetate; $1,1^{\prime}$-hexamethylenebis (5-[ $p$-chlorophenyl]

biguanide) diacetate])

Grass (optional; see Step 8)

Grit

Hand-feeding formula (e.g., ZuPreem) (optional; see Step 20)

Vegetables (fresh-cut; e.g., kale, lettuce, sprouts)

Yarn (optional; see Step 8)

Zebra finch seed

Equipment

Automatic light timer

Bedding (card stock, textured paper, or news print)

Some facilities might require an absorbent material such as Techboard Ultra (www.ssponline.com/techboard .html).

\footnotetext{
${ }^{1}$ Correspondence: melloc@ohsu.edu

(c) 2014 Cold Spring Harbor Laboratory Press

Cite this protocol as Cold Spring Harb Protoc; doi:10.1101/pdb.prot084780
} 
C.R. Olson et al.

Cloth bag/covers

Dishes for food, grit, and bathing

Flashlight

Light source for candling eggs

Metal wire cages

Nest boxes (e.g., Abbaseed N011)

Nesting material (e.g., coconut husk, hay, burlap)

Perches

Room with full-spectrum lighting (i.e., incandescent or LED)

Small incubator set at $30^{\circ} \mathrm{C}-32^{\circ} \mathrm{C}$ (optional; see Step 21)

Soundproof chamber (optional; see Step 13)

Water bottles

\section{METHOD}

Follow all animal welfare guidelines appropriate for your institution.

\section{Enclosure Setup, Care, and Cleaning}

1. Aim to maintain the zebra finches at typical laboratory temperatures of $20^{\circ} \mathrm{C}-25^{\circ} \mathrm{C}$, and $\sim 40 \%$ humidity, with a day-night cycle within the range $12 \mathrm{~h}: 12 \mathrm{~h}$ to $10 \mathrm{~h}: 14 \mathrm{~h}$.

In the wild, zebra finches experience considerably wider fluctuations and higher average temperatures than in the laboratory (Zann 1996), meaning that the laboratory might not be ideal for breeding (Schmidt 2010). Of greater concern is the low light intensity in animal facilities designed for rodent husbandry-hence, supplementation with full-spectrum lights is advisable. Day-night light cycles are important as continuous light conditions are known to result in health problems (Snyder et al. 2013).

2. House the finches in wire cages, with a minimum mesh of $12.7 \times 15.2 \mathrm{~mm}$, lined with bedding material. There are two main caging options:

- Cage dimensions of $35.6 \times 35.6 \times 45.7 \mathrm{~cm}$ (Fig. 1A,B) are adequate for a single breeding pair or five to six nonbreeding individuals.

Minimum cage sizes have not been established for this species (National Research Council [U.S.]. Committee for the Update of the Guide for the Care and Use of Laboratory Animals; National Research Council 2011), but cages that are long are preferred over those that are tall (Bateson and Feenders 2010).

- Alternatively, if control of paternity is not important, house up to eight pairs in a large communal flight cage $(244 \times 122 \times 213 \mathrm{~cm})$.

Communal cages can promote health and greater flight strength.

3. Place perches at varying heights throughout the cage and avoid placement above food, water, and grit (Fig. 1B).

4. Provide ad libitum access to food, water, and grit; supplement diet with green leafy vegetables and cooked eggs.

5. Ensure that empty seed husks do not restrict access to food by removing husks daily from seed dispensers.

6. Change drinking water daily, and sterilize water bottles twice weekly.

7. Refresh the bedding every $3 \mathrm{~d}$.

8. (Optional) Provide environmental enrichment.

i. Deposit natural fibers (grass, yarn, bark), in addition to raw vegetables and sprouts, on the floor of the cage to attract the interest of the finches.

ii. Place a wide, shallow dish of water on the floor of the cage-this will often be enthusiastically used for bathing. 

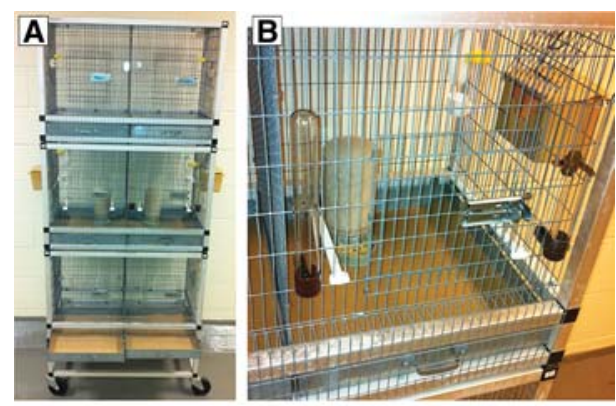

C

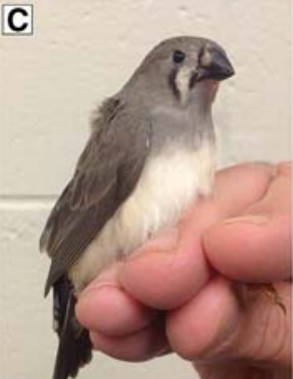

D
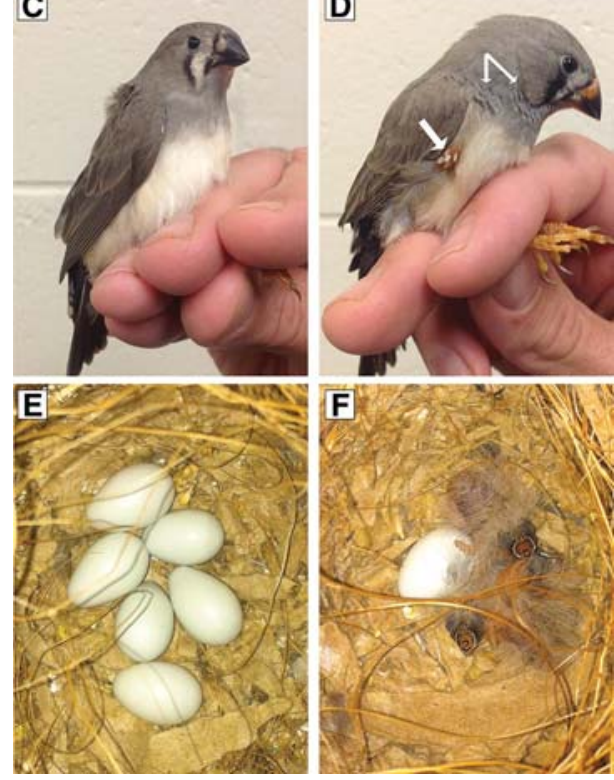

FIGURE 1. Care and breeding of the zebra finch, Taeniopygia guttata. (A) A six-plex cage that is designed to house six pairs of breeding birds; central cage dividers are removable to allow housing of five to six individuals. (B) Single housing unit from $A$ showing a paper-lined floor, water bottles, food dispensers, cuttlebone, and a nest box. $(C)$ Juvenile female. (D) Juvenile zebra finch exhibiting chestnut markings on the flank (thick arrow) and black stripes on the throat (thin arrows) that are diagnostic of young males. Note the absence of the orange cheek patch typical of adult males. (E) Clutch of six eggs in a nest composed of coconut fiber. $(F)$ Three zebra finch hatchlings on hatch day one and a single unhatched egg.

\section{Establishing a Colony}

9. Ideally, house the zebra finches in mixed-sex large-flight cages or aviaries.

This promotes exercise and allows the birds to interact with, and choose, mating partners-however, these mixed-housing conditions will result in juveniles acquiring songs from multiple males, in addition to their father.

10. Move the birds, as necessary, to separate fighting individuals and sequester breeding pairs.

Note that individual caging of birds is a source of stress (Bateson and Feenders 2010), and visual contact with other individuals should be maintained if isolation is necessary.

11. To catch birds, turn off the room lights and use a small flashlight for illumination; use a cloth bag or covered cage for transport of the birds.

The safest way to handle zebra finches is the bander's grip, where the bird's back is held against the palm of the investigator's hand, with the head sticking between the index and middle fingers (Members of the Joint Working Group on Refinement 2001).

Distinguishing Males and Females

12. Use the following criteria to sex zebra finches.

- Distinguish females by their generally tawny-gray color that fades into a whitish breast (see Fig. 1 in The Zebra Finch, Taeniopygia guttata: An Avian Model for Investigating the Neurobiological Basis of Vocal Learning [Mello 2014]).

- Identify males from females by the presence of an orange cheek patch after $\sim 35 \mathrm{~d}$ posthatching (dph).

In some color morphs, these cheek patches can be black, white, or even absent. 
C.R. Olson et al.

- Tell young males ( 20 dph; Fig. 1D) from females (Fig. 1C) by the presence of black and white stripes along the throat (Fig. 1D, small arrows), and chestnut markings on the flank (Fig. 1D, large arrow).

- Use molecular methods to sex nestlings by DNA isolation (e.g., from feathers), followed by polymerase chain reaction amplification (Soderstrom et al. 2007).

- Note that only males sing.

Breeding and Rearing of Juveniles

13. To breed birds most efficiently, place seven to eight pairs in a large cage (see Step 2) (Bateson and Feenders 2010).

If strict control over auditory and social input during the posthatching period is required, breeding can also be performed in smaller cages either with visual isolation from other birds or in acoustic isolation within soundproof chambers - it might be necessary to screen the population first to identify birds that will breed well under these conditions.

14. Place nest boxes near the inside top of the cage (Fig. 1B), with a small perch just external to the nest opening.

15. Provide nesting materials on the cage floor and in the nest box-we recommend that coconut husk or hay (cut to a length of $15 \mathrm{~cm}$ ) be formed into a loose nest and inserted by hand into the nest box.

Note that allowing a pair to build from scratch can result in poor-quality nests and lost eggs.

16. Monitor the cages for eggs.

Eggs are laid one per day over 2-7d. Clutch sizes range from three to eight eggs. Eggs are white and semitranslucent (Fig. 1E) and will have an air pocket visible on the wide end of the egg. Air pockets are 1-2 $\mathrm{mm}$ in diameter on the day the eggs are laid and become larger during incubation.

17. After egg-laying starts, remove unused nesting material from the cage floor to prevent further nest building over laid eggs.

Both parents might continue to add fiber and attend the nest during laying.

18. Monitor the cages during the incubation period. Confirm egg fertility by day 3 of incubation by candeling the eggs to observe the developing embryo.

Incubation begins when the final egg is laid. Zebra finch eggs require a 14-15d incubation period, during which both sexes can incubate the eggs, sometimes simultaneously. Females develop a brood patch for the transmission of heat to eggs. Eggs tend to lose $12 \%-15 \%$ of their mass during the incubation period (Rahn and Ar 1974). Humidity levels should be altered (up or down) if the egg mass varies considerably from this range.

19. Monitor the nestlings.

Chicks, which hatch $\sim 15-20 \mathrm{~d}$ after the eggs are laid, weigh $0.7-1.1 \mathrm{~g}$, are altricial, naked, and have closed eyes (Fig. 1F). Parents will usually brood chicks for 5-6 dph or until the chicks are capable of thermoregulation. By $\sim 8 \mathrm{dph}$, plumage is present, eyes are open and chicks become responsive to handling by the investigator. Because the chick's parents deliver food, no special neonatal diet is required, but chick health can benefit from supplementation with vegetables and chicken eggs.

In the event of nestling abandonment or unavailability of suitable foster nests, juveniles may be reared by hand, see Steps 21-23.

20. Leave the chicks with adults until they are able to feed on their own ( $\sim 30-35 \mathrm{dph})$. Avoid premature weaning as it can result in poor nutrition or death.

Note that chicks that are left with their parents beyond $\sim 50 \mathrm{dph}$ can interfere with the success of subsequent clutches.

Handrearing (Optional)

21. Move chicks to a small incubator set at $30^{\circ} \mathrm{C}-32^{\circ} \mathrm{C}$ on soft bedding.

22. Feed chicks hand-feeding formula (e.g., ZuPreem) at 2 -h intervals from 06.00 to $23.00 \mathrm{~h}$ for the first $5 \mathrm{~d}$, and at 3-h intervals after day 5 until the bird is able to feed itself. Deliver the food by syringe until the crop, which is visible through the skin at the base of the throat, appears full.

23. Change bedding between feedings. 
The zebra finch is a songbird species native to mainland Australia. It is a small bird-wild adult females weighing on average $12.5 \mathrm{~g}$, whereas males are lighter, averaging $12.2 \mathrm{~g}$ (Zann 1996). It is commonly used in the laboratory, particularly for studies of vocal learning and the associated neural and genetic mechanisms of such learning. In the wild, zebra finches typically live in large colonial flocks, yet form longterm pair bonds (Silcox and Evans 1982), with a moderate rate of generation of extrapaternity offspring (Birkhead et al. 1990). They provide biparental care, with breeding possible at an age of 4 mo (Austad 2011) and have a breeding frequency of three to four clutches per year. With appropriate care, they have an average lifespan of $\sim 4 \mathrm{yr}$ and can live up to $8 \mathrm{yr}$ or even longer (Austad 2011). Learned song is culturally transmitted from adults to juveniles (Feher et al. 2009; Fee and Scharff 2010), and husbandry practices are important for the normal development of this trait. Thus, there is a need for investigators to adopt good practices, as outlined here, for the successful rearing and breeding of zebra finches.

Proper animal husbandry is an essential requirement for studying vocal learning in zebra finches as young chicks cannot be purchased commercially and therefore must be bred in the laboratory. It is important to recreate environmental conditions that best mimic those conditions found in the zebra finches' natural habitat. Proper documentation of the social environment is also important to ensure experimental consistency across laboratories (Fee and Scharff 2010). Zebra finches are noisy and might need to be housed apart from other species that are sensitive to noise (Committee for the Update of the Guide for the Care and Use of Laboratory Animals; National Research Council 2011). In contrast with rodent husbandry practices, group housing is preferred over individual housing (Bateson and Feenders 2010; Schmidt 2010).

Male rivalries are generally peaceful, but can include aggressive singing and occasionally "bill fencing." Fighting is rare, but can occur with overcrowding, stress, and/or skewed sex ratios. Birds that are being picked-on typically show feather loss in the head and neck. In contrast, a sick bird can present puffed feathers, a wet or crusted-over cloaca, a frequently drooped head, or chronic lethargy. In these cases, such birds should be moved to individual housing for treatment and/ or recovery.

If a nest is provided, breeding will typically begin $\sim 1 \mathrm{wk}$ after pairing. Proper nesting materials should be provided to avoid the possible use of cage linings (e.g., paper) as nesting material, which often leads to laid eggs being covered. Unlike most avian species, zebra finches are minimally reliant on photoperiod for reproduction. Instead, the availability of food and water is believed to trigger reproduction. We note, however, that breeding can be encouraged by the use of a 14:10 h light:dark photoperiod, dietary supplementation with leafy greens, an increase in ambient temperature and humidity, and by occasional misting.

Zebra finches are tolerant of investigator intrusion during breeding, and nest abandonment is rare. However, because successful breeding requires nest box use for 5-6 wk, a request for an exception to the recommended cage washing guidelines of $2 \mathrm{wk}$ (in Committee for the Update of the Guide for the Care and Use of Laboratory Animals; National Research Council 2011) might be needed.

Finally, for additional detailed information concerning the proper care and maintenance of zebra finches in the laboratory, readers are referred to additional previously published resources (Zann 1996; Bateson and Feenders 2010; Schmidt 2010).

\section{ACKNOWLEDGMENTS}

We thank the Oregon Health and Science University Department of Comparative Medicine for providing proper care for our zebra finch colony and for helping with the development of the housing and rearing protocols described in this protocol. 


\section{C.R. Olson et al.}

\section{REFERENCES}

Austad SN. 2011. Candidate bird species for use in aging research. ILAR J 52: 89-96.

Bateson M, Feenders G. 2010. The use of passerine bird species in laboratory research: Implications of basic biology for husbandry and welfare. ILAR J 51: 394-408.

Birkhead TR, Burke T, Zann R, Hunter FM, Krupa AP. 1990. Extra-pair paternity and intraspecific brood parasitism in wild zebra finches Taeniopygia guttata, revealed by DNA fingerprinting. Behav Ecol Sociobiol 27: $315-324$.

Committee for the Update of the Guide for the Care and Use of Laboratory Animals; National Research Council. 2011. Guide for the care and use of laboratory animals National Academies Press, Washington, D.C.

Fee MS, Scharff C. 2010. The songbird as a model for the generation and learning of complex sequential behaviors. ILAR J 51: 362-377.

Feher O, Wang H, Saar S, Mitra PP, Tchernichovski O. 2009. De novo establishment of wild-type song culture in the zebra finch. Nature 459: 564-568.

Mello CV. 2014. The zebra finch, Taeniopygia guttata: An avian model for investigating the neurobiological basis of vocal learning. Cold Spring Harb Protoc doi: 10.1101/pdb.emo084574.
Members of the Joint Working Group on Refinement. 2001. Laboratory birds: Refinements in husbandry and procedures. Fifth report of BVAAWF/FRAME/RSPCA/UFAW Joint Working Group on Refinement. Lab Anim 35: 1-163.

Rahn H, Ar A. 1974. The avian egg: Incubation time and water loss. Condor 76: $147-152$.

Schmidt MF. 2010. An IACUC perspective on songbirds and their use in neurobiological research. ILAR J 51: 424-430.

Silcox AP, Evans SM. 1982. Factors affecting the formation and maintenance of pair bonds in the zebra finch, Taeniopygia guttata. Anim Behav 30: $1237-1243$.

Snyder JM, Molk DM, Treuting PM. 2013. Increased mortality in a colony of zebra finches exposed to continuous light. J Am Assoc Lab Anim Sci 52: 301-307.

Soderstrom K, Qin W, Leggett MH. 2007. A minimally invasive procedure for sexing young zebra finches. J Neurosci Methods 164: 116119.

Zann RA. 1996. The zebra finch: A synthesis of field and laboratory studies Oxford University Press, Oxford. 


\section{Proper Care, Husbandry, and Breeding Guidelines for the Zebra Finch, Taeniopygia guttata}

Christopher R. Olson, Morgan Wirthlin, Peter V. Lovell and Claudio V. Mello

Cold Spring Harb Protoc; doi: 10.1101/pdb.prot084780 originally published online October 23, 2014

\begin{tabular}{rc}
$\begin{array}{r}\text { Email Alerting } \\
\text { Service }\end{array}$ & Receive free email alerts when new articles cite this article - click here. \\
\hline $\begin{array}{r}\text { Subject } \\
\text { Categories }\end{array}$ & $\begin{array}{c}\text { Browse articles on similar topics from Cold Spring Harbor Protocols. } \\
\text { Avian (39 articles) } \\
\text { Emerging Model Organisms (321 articles) } \\
\text { Laboratory Organisms, general (923 articles) }\end{array}$ \\
\hline
\end{tabular}

